\title{
Groningen field, past, present and future
}

\author{
H.J.M. Roels
}

Managing Director, NAM

A summary will be presented of the key milestones in the development of the Groningen field. From discovery in 1959, through its rapid development during the sixties and seventies, the subsequent production decline as result of the "Small Fields Policy", its current balancing role, the recent construction of two Underground Gas Storages and finally the Groningen Long Term project.

\section{The past}

With the discovery in 1959, the giant Groningen field rapidly became the favorite energy supplier in The Netherlands and neighboring countries:

\section{The Present}

Over time, more and more small fields were added to the Dutch gas portfolio. However, Groningen still produces some $50 \%$ of the Dutch annual production whilst providing the ever important balancing function:

In 1998, the Groningen reservoir operated by some 250 field staff, produced its 1500 billionth $\mathrm{m}^{3}$ and is now more then half empty. To allow the continued functionality of the Groningen System despite its reduced reservoir pressure, three underground gas storages (UGS) were recently completed in Alkmaar (op-

\section{Groningen Historical and Future Volumes}

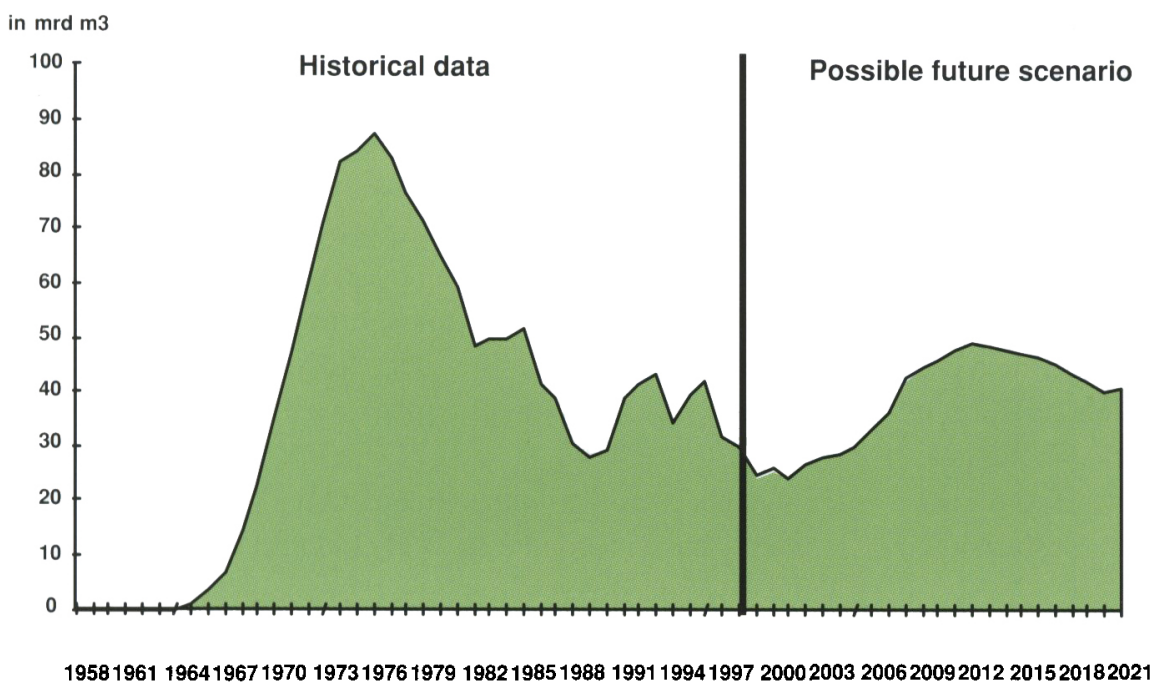

In the early seventies this trend was reversed with the development of the "Small Fields Policy" where incentives were provided to the private industry to explore and produce small gas accumulations. In this development, the Groningen field takes the role of balance supplier of volume and capacity. The small fields being developed economically through allowing high load-factor production with Groningen providing the balance between (heavily fluctuating) demand and supply. Up till now, the small fields have added some 1300 billion $\mathrm{m}^{3}$ to the Dutch reserves. Reserves, which wouldn't have been developed without the back-up of Groningen. erated by BP Amoco), at Grijpskerk and at Langelo. The Langelo and Grijpskerk storages are amongst the largest in the world. To meet the most severe peak demand, the Groningen system including its three gas storages, is currently capable of producing at a rate of over 500 million $\mathrm{m}^{3} / \mathrm{d}$, with the ability to "ramp-up" its production rate by $120 \mathrm{mln} \mathrm{m} / \mathrm{d}$ in less then an hour. 


\section{January '97 Production swings Groningen and Non-Groningen supplies}

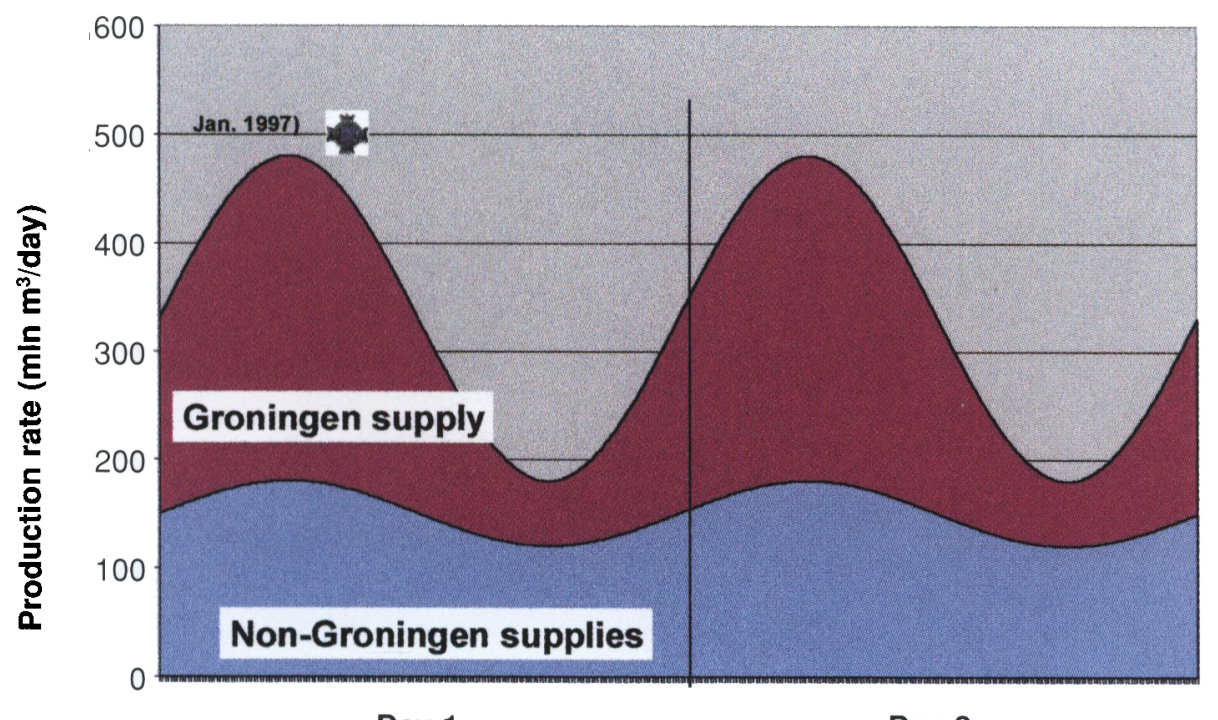

Day 1

Day 2

NAM guarantees Gasunie reliability for the gas supply from the Groningen system, that translates into a maximum of one hour "downtime" in fifty years allowing industry as well as private consumers to rely on security of energy supply. It goes without saying that, thus far, the system has never failed! To ensure the function of the Groningen system in providing balance volume, balance capacity and "ramp-up", to date, some Nfl 16 billion has been invested in the system.

\section{The Future}

To allow the Groningen System to continue its current role, 25-year future demand scenarios are built. These scenarios represent the previously mentioned daily, weekly and seasonal demands for each individual year. These scenarios are then translated in "Load Duration Curves" which define both the capacity (the left axis) as well as the volume demand (the area underneath) requirements:

\section{The Load Duration Curve}

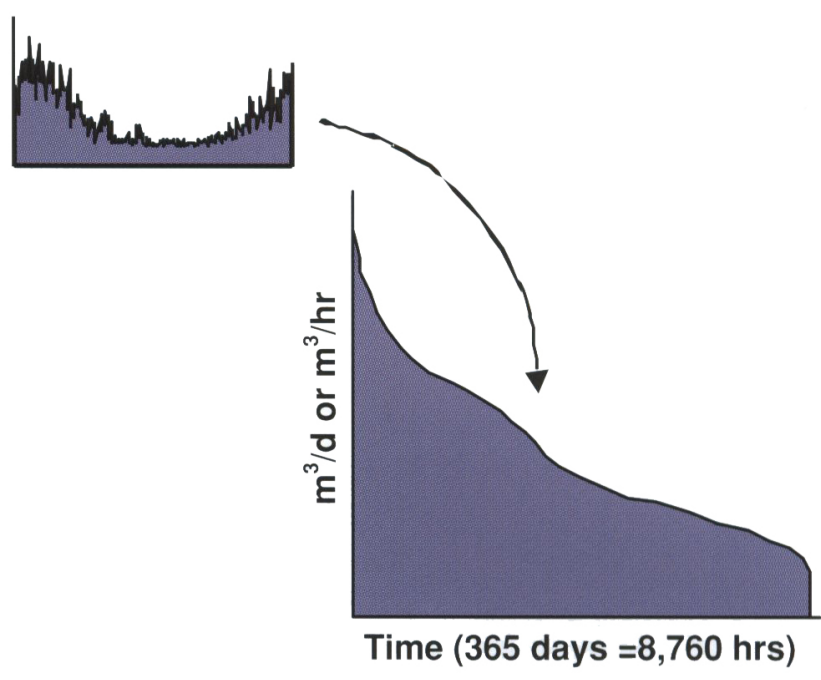

Currently, the load duration curve is "filled" with the Gasunie LNG plant at the top, the three UGSs below that and the small fields at the bottom. The area inbetween represents the capabilities of the Groningen system, both in volume and capacity supply. However, due to the continuing declining reservoir pressure we foresee a gap arising early in the next millenium, which will require additional capacity measures in the Groningen field. We have therefore embarked on the so-called GLT (Groningen Long Term) program, providing compression on each of the field locations. Through this latest program of compression installation, Groningen, which is already the heart of the Dutch circulation system for primary energy, will be 


\section{Tjuchem Compressor (23 MW)}

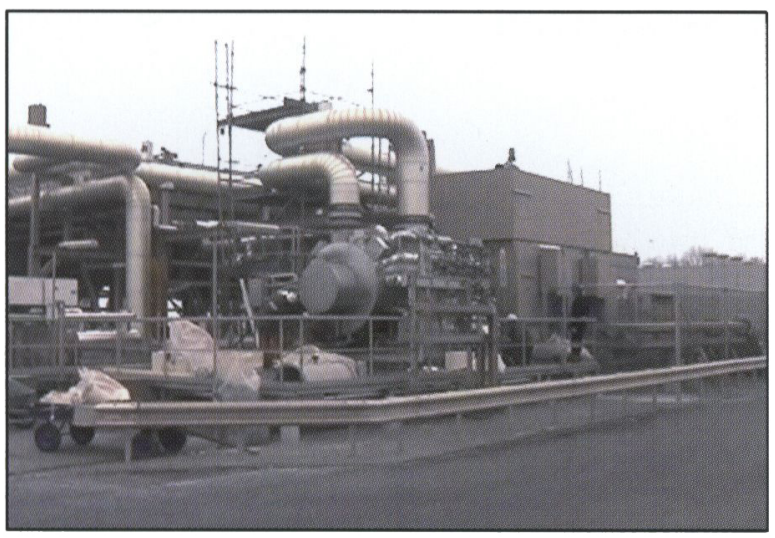

given a new lease of life. That heart will quicken and slow its electrically powered beat as the country awakes, works, feeds and rests. For decades to come. 